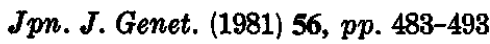

\title{
Variation of DNA content in Asian rice
}

\author{
By Yasuo Nagato ${ }^{1)}$, Koji Yamamoto and Hideki Yamashita ${ }^{2)}$ \\ Laboratory of Plant Breeding, Faculty of Agriculture, \\ University of Tokyo, \\ Tokyo 113
}

(Received June 11, 1981)

\begin{abstract}
We examined the variation of DNA content in Asian rice; wild species, Oryza perennis, cultivated species, $O$. sativa, and the wild-cultivated intermediate Jeypore strains. DNA contents were estimated Feulgen microspectrophotometrically and chemically. In addition, nuclear volume was recorded which was known to correlate positively with DNA content. There existed strong correlations between the estimates obtained by the above three methods, showing a reliability of the present measurements.

In each species, considerably wide variation of DNA content was detected which was not due to random error of the measurements. Though variations among strains overlapped between $O$. perennis, Jeypore strains and $O$. sativa, they showed an evolutionary tendency. Oryza perennis strains generally had the higher DNA contents than $O$. sativa strains and the intermediate Jeypore strains had the intermediate values. Therefore, we consider that DNA content of Asian rice has decreased during evolution (domestication). In Asian rice, reduction of DNA content is parallel to the reduction of the globular period of embryo which means the decrease of developmental instability. The reductional nature of DNA content during evolution is also observed in the process of speciation of other species and as well in the evolution of monocotyledons at the order level. This suggests that many evolutionary changes in plants, if not all, are connected with the decrease of DNA content.
\end{abstract}

\section{INTRODUCTION}

In recent years, DNA content per cell, per nucleus or per chromosome has been examined in many species, revealing that there exists a considerable variation of DNA content within a family, genus or even species (Rees et al. 1966; Chooi 1971; Bennett 1972; Price et al. 1973; Furuta et al. 1974; Price and Bachmann 1975). Though the mechanism of change in DNA content is not fully understood, the evolutionary significance of the change in DNA amount was pointed out by some investigators. For example, nuclear DNA content is positively correlated with the durations of mitosis and meiosis and so it is lower in annual species than in perennial species (Bennett 1972). In addition, Price and Bachmann (1975) discussed that specialized annual species

1) Present address: Experimental Farm, Faculty of Agriculture, University of Tokyo, Tanashi 188.

2) Present address: Ministry of the Agriculture, Forestry and Fishery, Tokyo 100. 
of Microseris was derived from $M$. laciniata through the decrease of DNA content, on the other hand, perennial Phalacroseris Bolanderi evolved from $M$. laciniata through the increase of DNA content. In boreal forest plants of Canada, DNA content is inversely related to the phylogenetic advancement (El-Lakany and Dugle 1972). Belford and Thompson (1981a, b) revealed that the extensive deletion of DNA has occurred during evolution of Atriplex species. In Allium, both gain and loss of nuclear DNA were observed (Jones and Rees 1968). Above results suggest that DNA content per nucleus or chromosome is changeable in relatively unconstrained manner. Though there must exist upper and lower limits in DNA content, plants must have changed their DNA content to be more adaptive in the course of evolution.

In the present study, we examined the variation of DNA content in Asian rice. It is known that the cultivated species, $O$. sativa $L$., evolved from wild species, O. perennis Moench. The strains collected at Jeypore Tract in India (Jeypore strains) are known to show a wide variation ranging from wild to cultivated types (Oka and Chang 1962). We estimated DNA amount per nucleus and cell so as to clarify the extent of variation in the above species and to know whether the evolution (domestication) of Asian rice stated above is related to the change of DNA content or not.

Katayama (1967) measured DNA contents of many species in the genus Oryza. However, he examined only one or a few strains of each species and the extent of intraspecific variation is not clear.

In estimating DNA content per nuclues or cell, the trouble is the low reliability of the data obtained. In the present experiment, we employed two methods; Feulgen microspectrophotometry and spectrophotometry of chemically extracted DNA. Furthermore, we measured nuclear volume which is known to correlate positively with DNA content (Van't Hof and Sparrow 1963; Price 1976). And we consider that the data of DNA content are reliable enough when the data obtained by the above three measurements are significantly correlated with one another.

\section{MATERIALS AND METHODS}

Seeds of $O$. perennis, $O$. sativa and Jeypore strains were used as materials. The number of strains used for three methods is summarized in Table 1. Sterilized seeds were germinated on moist filter paper at $30^{\circ} \mathrm{C}$ for two to four days and the root tips of radicles were excised.

Cytophotometric measurement of nuclear DNA content by Feulgen microspectrophotometry (MSP)

Root tips were treated with a fixative containing picric acid (Östergren and Heneen 1962), sectioned at $12 \mu \mathrm{m}$ after embedding in paraffin, and hydrolyzed 
Table 1. Number of strains of Asian wild and cultivated rices used for three determinations

\begin{tabular}{lccc}
\hline \multicolumn{1}{c}{ Species } & MSP & $\begin{array}{c}\text { Modified STS } \\
\text { method }\end{array}$ & Nuclear volume \\
\hline $\begin{array}{l}\text { O. perennis } \\
\text { Jeypore strains }\end{array}$ & 25 & 3 & 25 \\
$\quad$ wild & 16 & 1 & 16 \\
$\quad$ cultivated & 18 & 4 & 18 \\
O. sativa & & & \\
$\quad$ Indica & 24 & 6 & 24 \\
$\quad$ Japonica & 25 & 6 & 25 \\
\hline Total & 108 & 20 & 108 \\
\hline
\end{tabular}

in $1 \mathrm{~N} \mathrm{HCl}$ at $60^{\circ} \mathrm{C}$ for five minutes after the removal of paraffin. They were stained with Schiff's reagent and mounted with balsam. DNA content per nucleus was estimated by measuring the absorbance at $560 \mathrm{~nm}$ which showed maximal absorbance, using Olympus microspectrophotometer (Model MMSPTU). Measurement was carried out on more than 30 interphase nuclei of each strain. Nuclei examined were randomly chosen and so their DNA level varied from $2 \mathrm{C}$ to $4 \mathrm{C}$. The data obtained by this method were reliable within an error less than $10 \%$.

\section{Chemical measurement of cellular DNA content}

The excised root tips about $1 \mathrm{~mm}$ long of each strain were divided into two groups; one for DNA extraction and the other for counting the number of cells.

About 300 root tips were homogenized with Ohtake ultrasonicator (Sonicator 5200). The extraction of DNA from the homogenates was carried out by the modified Schmidt-Thannhauser-Schneider (STS) method (Mizuno and Whitely 1968). The absorbance of extracted DNA at $230-300 \mathrm{~nm}$ was measured with Hitachi spectrophotometer (Model 200-10). The maximal absorbance of extracted DNA existed at about $265 \mathrm{~nm}$. Then the difference between maximal absorbance and the absorbance at $300 \mathrm{~nm}\left(\Delta_{\max -300 \mathrm{~nm}}\right)$ was calculated. The absolute DNA amount was determined by comparing $A_{\max -300 \mathrm{~nm}}$ with the sample DNA of calf thymus (Sigma Chemical Co. Ltd.).

In order to estimate the number of cells composing the root tips used for DNA extraction, 30-50 root tips were macerated in $1 \mathrm{~N} \mathrm{HCl}$ at $75^{\circ} \mathrm{C}$ for an hour and broken into single cells with a syringe. Then, the number of cells in a unit volume were counted using a hemocytometer under a microscope. Averaged number of cells of 30 countings were used for calculating DNA content per cell. 
In this measurement, cells were randomly collected which contained nuclear DNA ranging from $2 \mathrm{C}$ to $4 \mathrm{C}$. In Allium, mean DNA content per cell nearly equals 3C nuclear DNA content (Van't Hof 1965). Therefore, DNA level obtained by this method can be regarded as 3C. DNA cntent per cell measured by this method fluctuated about $10 \%$ within a strain.

\section{Measurement of nuclear volume}

Root tips were stained with Schiff's reagent in the same manner as described in Feulgen microspectrophotometry. As the shape of nucleus in the apical meristem is not spherical and varies widely, interphase nuclei in the young cortical region were used for the measurement where nuclei were spherical and divided frequently. The diameters of more than 30 nuclei of each strain were averaged. Then we calculated nuclear volume from the diameter of nucleus regarding it as a sphere.

\section{RESULTS}

DNA contents estimated by three methods

There existed a strong correlation between data obtained by MSP and the modified STS method (Fig. 1). MSP measures DNA in nucleus and the modified STS method, on the other hand, measures that in cell including extranuclear

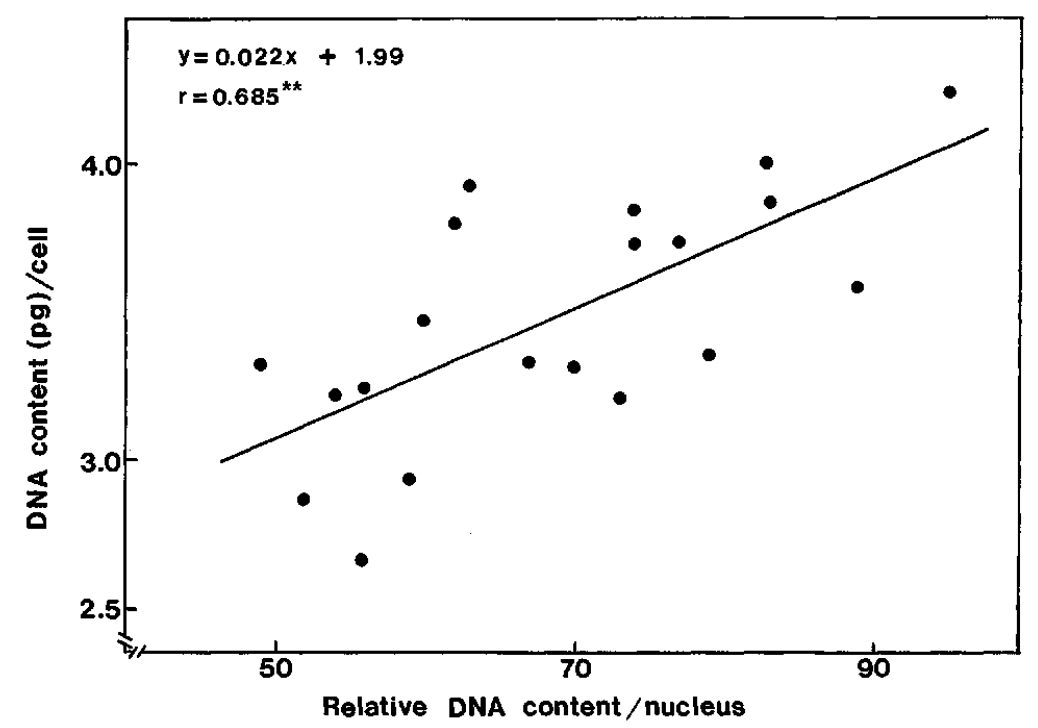

Fig. 1. Correlation of DNA contents per nucleus estimated by Feulgen microspectrophotometry and per cell estimated by modified STS method in Asian wild and cultivated rices.

** Significant at $1 \%$ level. 


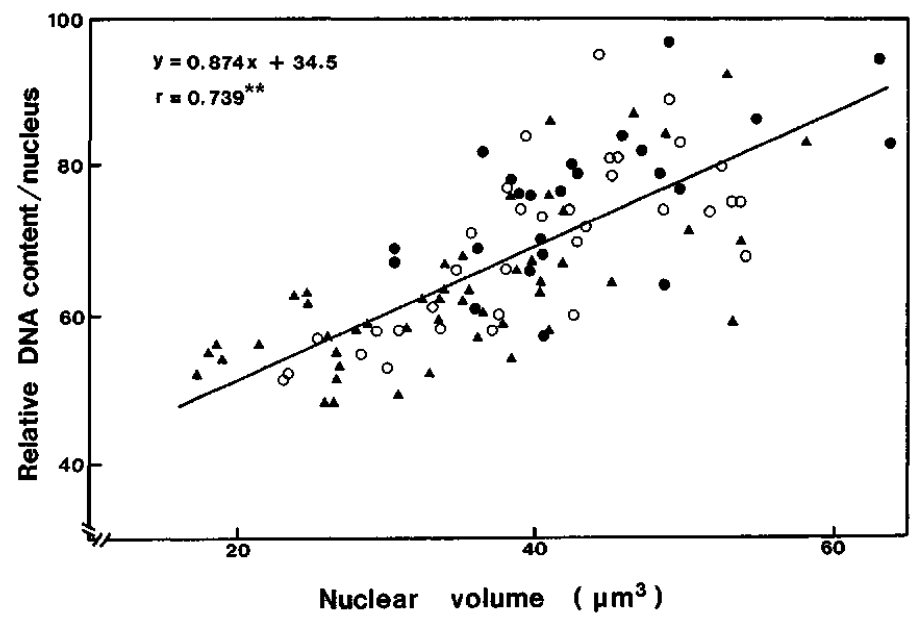

Fig. 2. Correlation between nuclear volume and relative DNA content per nucleus estimated by Feulgen microspectrophotometry in Asian wild and cultivated rices.

- - O. perennis, O-Jeypore strains, $\Delta-O$. sativa

** Significant at $1 \%$ level.

DNA. This difference is negligible as the amount of extranuclear DNA is very small. As Fig. 2 shows, nuclear volume also positively correlates with DNA content and can be satisfactorily used for estimating DNA content. These results show that the estimated DNA content in the present experiment is reliable.

In the present experiment, chemical extraction was carried out on only 20 strains for confirming the reliability of the measurement by MSP. Therefore data by MSP are mainly used in the followings.

From Fig. 1, relative nuclear DNA content $(\mathrm{x})$ is transformed into cellular DNA content in $\mathrm{pg}(\mathrm{y})$ by the following equation

$$
\mathrm{y}=0.022 \mathrm{x}+1.99 \text {. }
$$

\section{Intraspecific variation}

There existed a wide variation of DNA content in each species (Fig. 3). In O. perennis, cellular DNA content ranged from 3.2 to $4.1 \mathrm{gg}$, in Jeypore strains, from 3.1 to 4.1, and in $O$. sativa, from 3.0 to 4.0. In Japonica of $O$. sativa, the variation was relatively narrow excepting one strain (Norin-29) which showed extremely high DNA content.

In Jeypore strains, cultivated type did not differ from wild type in DNA content. On morphological characters, too, they differ continuously and can not be strictly distinguished each other. On the other hand, in $O$. sativa, Indica and Japonica types differed significantly (Fig. 3, Tables 2 and 3). They differed significantly also in nuclear volume (Fig. 4). 




Fig. 3. Frequency distribution of relative DNA content per nucleus measured by Feulgen microspectrophotometry in Asian wild and cultivated rices. Arrows indicate mean values.

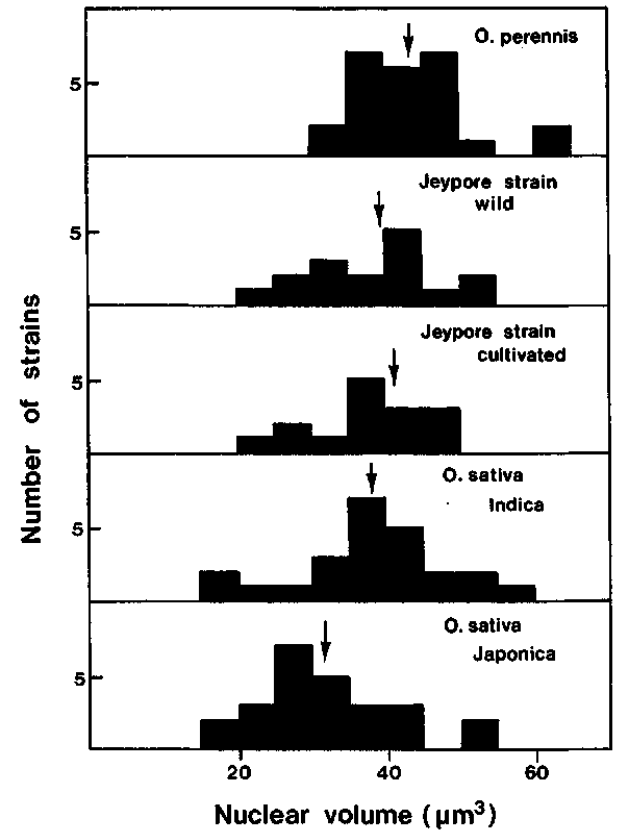

Fig. 4. Frequency distribution of nuclear volume in Asian wild and cultivated rices. Arrows indicate mean values. 


\section{Interspecific variation}

Though intraspecific variation of DNA content in each species overlapped each other, there existed a distinct tendency in the difference of the mean values. That is, wild $O$. perennis contains the highest mean DNA content ( $3.7 \mathrm{pg} /$ cell), cultivated species, O. sativa, the lowest $(3.4 \mathrm{pg} / \mathrm{cell})$ and Jeypore strain, intermediate (3.5 pg/cell) (Fig. 3, Tables 2 and 3). The same tendency was also observed in the nuclear volume (Fig. 4). Therefore, it is concluded that in Asian rice, mean DNA content has decreased in the course of speciation (domestication). This does not immediately mean that in the evolution of Asian rice, the change in DNA content is inevitably of reductional nature. That is, some strains might increase their DNA content, but more strains have decreased their DNA content during evolution.

Furthermore, wide intra- and interspecific variations in DNA content show that DNA amount of a chromosome is easily modified, because all the strains examined have the same chromosome number $(2 n=24)$.

Table 2. Relative nuclear DNA content in

Asian wild and cultivated rice strains measured by MSP

\begin{tabular}{cc}
\hline Species & Mean \pm S.D. \\
\hline O. perennis & $76.2 \pm 9.5$ \\
Jeypore strains & $69.5 \pm 11.1$ \\
wild & $69.1 \pm 11.9$ \\
cultivated & $69.9 \pm 11.0$ \\
O. sativa & $63.1 \pm 10.5$ \\
Indica & $66.5 \pm 10.8$ \\
Japonica & $60.0 \pm 9.0$ \\
\hline
\end{tabular}

Table 3. $t$-test for the difference in the relative nuclear DNA content between strain groups

\begin{tabular}{lcc}
\hline \multicolumn{1}{c}{ Comparison } & d.f. & t-value \\
\hline O. perennis-Jeypore strains & 57 & $2.45^{*}$ \\
O. perennis-O. sativa & 72 & $5.36^{* *}$ \\
$\begin{array}{l}\text { Jeypore strains-O. sativa } \\
\text { Jeypore strains }\end{array}$ & 81 & $2.63^{* *}$ \\
$\quad$ wild-cultivated & 32 & 0.20 \\
$\begin{array}{l}\text { O. sativa } \\
\quad \text { Indica-Japonica }\end{array}$ & 47 & $2.29^{*}$ \\
\hline
\end{tabular}

*, $* *$ Significant at $5 \%$ and $1 \%$ level, respectively. 


\section{DISCUSSION}

Results obtained in the present experiment show that there exists a wide variation of DNA content within each species. In the past, it was generally considered that DNA content was fixed within species and the fluctuation was regarded as experimental error. But we can not attribute the intraspecific variation of DNA content in rice solely to the experimental errors, because DNA contents obtained by two different methods correlate strongly with each other. In addition, it is well known that change in DNA amount is inducible environmentally, e.g. by the application of fertilizer, as shown in flax (Cullis 1977). At the molecular level, it is recently considered that DNA amount is not strictly fixed within species of higher organisms and some classes of DNA can replicate freely without any dependence on other DNA. The free replication results in the repetitive base sequences of DNA in nucleus, and these classes of DNA are called "selfish" DNA or "parasitic" DNA (Doolittle and Sapienza 1980; Orgel and Crick 1980). In higher organisms, it is established that chromosome is a linear array of DNA fragments which behave as units of self-replication and gene expression. Furthermore, the mechanism by which replicated DNAs are distributed equally among two daughter cells at mitosis is independent from that of DNA replication. This suggests that changes in the quantity and quality of DNA in a chromosome do not offer any trouble on cell division.

However, DNA amount will not change freely in a nucleus. As shown in Tables 2 and 3 and Fig. 2, there is an evolutionary reduction in the amount of DNA from perennial to annual species. The first author of the present paper has reported that the period of globular stage of embryo has been reduced during evolution of Asian rice, and the stage is more unstable than the following stage at which morphological differentiation occurs (Nagato 1979, 1981). This suggests that Asian rice evolved toward acquiring the developmental stability of embryo. In the case of rice, domestication of wild type has occurred during evolution bringing about the change from perennial to annual habit. We consider that the evolutionary reduction in DNA amount must be related to adaptation, e.g. an increase in responsiveness to fertilizer, an increase in developmental stability of embryo and so on.

In order to know the evolutionary change of monocotyledons in DNA content at the higher level than species, data obtained by other investigators were recalculated into DNA content per chromosome and averaged within order (Fig. 5). The figure shows that there is an evolutionary reduction of DNA content per chromosome at the order level of monocotyledons. There are many examples in animal and plant kingdoms showing that primitive form has higher DNA value (C-value) than the advanced form. The oddness of this phenomenon is expressed as "C-value paradox" (Cavalier-Smith 1980). 


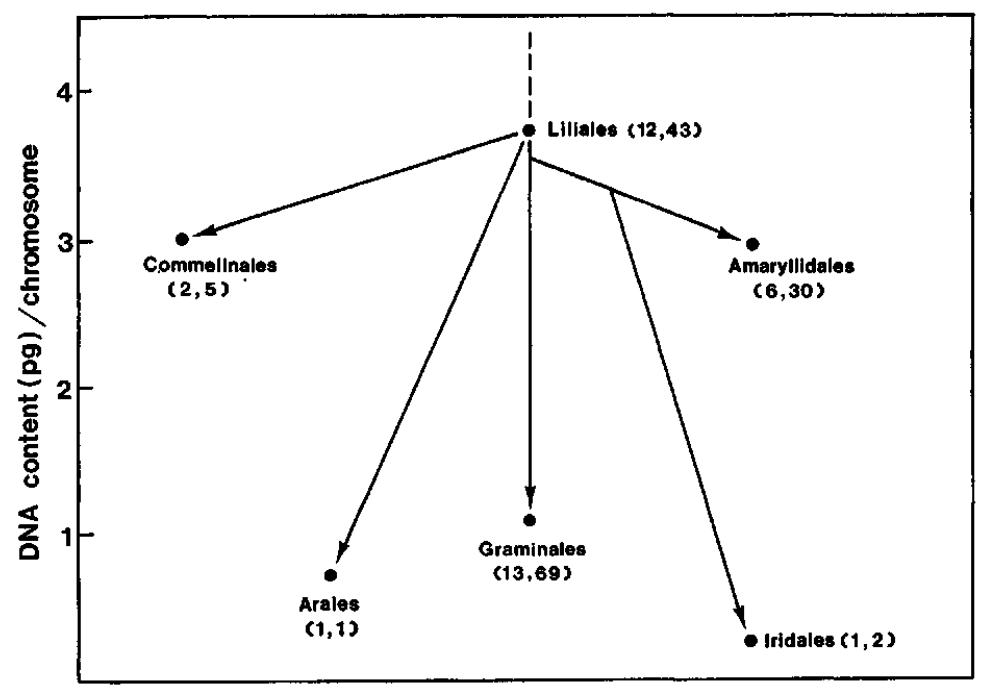

Fig. 5. Change of DNA content in the course of evolution in monocotyledons at the order level based on the classification system of Hutchinson (1959). Figures in parenthesis designate numbers of genera and species examined. Information from Sparrow and Evans (1961), Van't Hof and Sparrow (1963), Rees and Walters (1965), Sparrow et al. (1965), Van't Hof (1965), Baeteke et al. (1967), Rees and Jones (1967), Jones and Rees (1968), Paroda and Rees (1971), Bennett (1972) and Furuta (1975).

There is a view that C-value paradox can be explained by the increment of some classes of DNA ("junk" DNA (Ohno 1973)) whose effects on phenotype are small or zero, or "selfish" DNA which does not make any specific contribution to the phenotype. Repetitive DNA base sequences in a genome (Britten and Kohne 1968) are regarded as one of the candidates for these classes of DNA. On the other hand, there is an opposite view that the reduction in DNA content play a prominent role in the evolution of genome, since phenotypic specialization is often associated with the decrease of DNA content (Hinegardner 1976). Recently, Belford and Thompson (1981a, b) have reported that non repetitive single copy DNAs are subjected to extensive deletion during evolution in Atriplex. If the change in DNA content during evolution was resulted from the reccurrent reproduction of "selfish" DNA, it would be that the direction of the change was more obscure at the higher level than at the lower level of taxon. However it is clear that mean DNA content has decreased in the speciation of Asian rice. The reductional nature of DNA amount during evolution is more obvious at the order level of monocotyledons as in Fig. 5. Therefore, we consider that the latter view is more probable to explain C-value paradox.

Of course, C-value paradox is not explained by the reduction of DNA content alone. Increase of DNA amount must play an important role in the evolution of genome. In the course of macroevolution leading to adaptive radiation, 
increase of DNA content is expected, because many new adaptive characters require more complicated systems of genes. It seems that increment of DNA amount offers raw materials for new genes or new genic systems, on the other hand, the reduction results in the decrease of redundancy and the creation of new interactions between genes. We consider that in order to explain C-value paradox, the role of increment and reduction of DNA content must be clarified in relation to the creation and specialization of genic systems in which many genes work cooperatively.

The seeds of Oryza perennis, Jeypore strains and O. sativa (Indica) were kindly provided by Dr. H. I. Oka and Dr. H. Morishima, National Institute of Genetics, Mishima and those of $O$. sativa (Japonica) by Dr. K. Maruyama, National Institute of Agricultural Science, Tsukuba. Dr. T. Hayashi kindly permitted us to use microspectrophotometer in the College of General Education, University of Tokyo. We are also grateful to Prof. T. Nakajima, University of Tokyo for his helpful advice.

\section{REFERENCES}

Baeteke, K. P., Sparrow, A. H., Naumann, C. H. and Schwemmer, S. S. (1967) The relationship of DNA content to nuclear and chromosome volumes and to radiosensitivity (LD $\left.\mathrm{LD}_{50}\right)$. Proc. Natl. Acad. Sci. USA 58, 533-540.

BeLford, H. S. and Thompson, W. F. (1981a) Single copy DNA homologies in Atriplex L. I. Cross reactivity estimates and the role of deletions in genome evolution. Heredity 46, 91108.

BELford, H. S. and Thompson, W. F. (1981b) Single copy DNA homologies in Atriplex L. II. Hybrid thermal stabilities and molecular phylogeny. Heredity 46, 109-122.

BENNETT, M. D. (1972) Nuclear DNA content and minimum generation time in herbaceous plants. Proc. Roy. Soc. Lond. B 181, 109-135.

Britten, R. J. and Kohne,D. E. (1968) Repeated sequences in DNA. Science 161, 529-540.

Cavalier-Smith, T. (1980) How selfish is DNA ? Nature 285, 617-618.

CHоOI, W. Y. (1971) Variation in nuclear DNA content in the genus Vicia. Genetics 68, 195-211.

CuLlis, W. Y. (1977) Molecular aspects of the environmental induction of hereditable changes in flax. Heredity 38, 129-154.

Doolitile, W. F. and SAPIENZA, C. (1980) Selfish genes, the phenotype paradigm and genome evolution. Nature 284, 601-603.

EL-Lakany, M. H. and Dugle, J. R. (1972) DNA content in relation to phylogeny of selected boreal forest plants. Evolution 26, 427-434.

FuRUTA, Y. (1975) Quantitative variation of nuclear DNA in genus Aegilops. Jpn. J. Genet. 50, 383-392.

Furuta, Y., Nishikawa, K. and Tanino, T. (1974) Stability in DNA content of AB genome component of common wheat during the past seven thousand years. Jpn. J. Genet. 49, 179-187.

HINEGARDNER,R. (1976) Evolution of genome size. In Molecular evolution (ed. F. J. Ayala), pp. 179-199. Sinauer Assoc. Inc., Sunderland, Mass.

Hutchinson, J. (1959) The families of flowering plants, I, II. 2nd ed. Univ. Press, Oxford.

Jones, R. N. and ReEs, H. (1968) Nuclear DNA variation in Allium. Heredity 23, 591-605.

Katayama, T. (1967) Relative amounts of deoxyribonucleic acid (DNA) per nucleus of diploid species in Oryza. Japan. J. Breed. 17, 21-25.

Mizuno, S. and WhITELEY, H. R. (1968) Nuclear fraction of Bacillus subtilis as a template for nucleic acid synthesis. J. Bacteriol. 95, 1221-1237.

NaGato, Y. (1979) Stability of embryo growth in rice. Japan. J. Breed. 29, 23-32.

NAGATo, Y. (1981) Embryological studies on the evolutionary path in Asian rice. Bot. Gaz. 142, 
274-278.

OHNo, S. (1973) So much "junk" DNA in our genome. Brookhaven Symp. Biol. 25, 366-370.

OKA, H. I. and ChANG, W. T. (1962) Rice varieties intermediate between wild and cultivated forms and the origin of the Japonica type. Bot. Bull. Acad. Sinica 3, 109-131.

ORGEL, L. E. and CRICK, F. H. C. (1980) Selfish DNA: the ultimate parasite. Nature 284, 604607.

ÖsTERGREN, G. and HENEEN, W. K. (1962) A squash technique for chromosome morphological studies. Hereditas 48, 332-341.

Paroda, R. S. and ReEs, H. (1971) Nuclear DNA variation in Eu-sorghums. Chromosoma 32, 353-363.

PrICE, H. J. (1976) Evolution of DNA content in higher plants. Bot. Rev. 42, 27-52.

Price, H. J., Sparrow, A. H. and Nauman, A. F. (1973) Evolutionary and developmental considerations of variability of nuclear parameters in higher plants. I. Genome volume, interphase chromosome volume, and estimated DNA content of 236 gymnosperms. Broolchaven Symp. Biol. 25, 390-421.

Price, H. J. and Bachmann, K. (1975) DNA content and evolution in the Mieroserinae. Amer. J. Bot. 62, 262-267.

Rees, H., Cameron, F. M., Hazarika, M. H. and Jones, G. H. (1966) Nuclear variation between diploid angiosperms. Nature 211, 828-830.

ReEs, H. and Jones, G. H. (1967) Chromosome evolution in Lolium. Heredity 22, 1-18.

REES, H. and WALters, M. R. (1965) Nuclear DNA and the evolution of wheat. Heredity 20 , 73-82.

Sparrow, A. H. and Evans, H. J. (1961) Nuclear factors affecting radiosensitivity. I. The influence of nuclear size and structure chromosome component, and DNA content. Brookhaven Symp. Biol. 14, 76-100.

Sparrow, A. H., Sparrow, R. C., Thompson, K. H. and Schairer, L. A. (1965) The use of nuclear and chromosomal variables in determining and predicting radiosensitivities. In The use of induced mutations in plant breeding, Suppl. to Radiat. Res. 5, pp. 101-132.

VAN'T HOF, J. (1965) Relationships between mitotic cycle time duration, $\mathrm{S}$ period duration and the average rate of DNA synthesis in the root-tip meristem cells of several plants. Exptl. Cell Res. 39, 48-58.

VAN'T HoF, J. and SPARROW, A. H. (1963) A relation between DNA content, nuclear volume, and minimum mitotic cycle time. Proc. Natl. Acad. Sci. USA 49, 897-902. 